\title{
Mixed Convection Heat Transfer from a Short Vertical Cylinder Placed in a Cross Flow
}

\author{
Y. Rihan and S. El-Kholy \\ Hot Lab. Center, Atomic Energy Authority, Egypt \\ E-mail: yarihan159@yahoo.com
}

\begin{abstract}
Experimental study of mixed free and forced convection heat transfer from a vertical heated cylinder placed in a crossflow is studied for Reynolds number from $1.1 \times 10^{3}$ to $3.3 \times 10^{4}$ and Prandtl number 0.7 . The average Nusselt number is calculated and correlated with the Reynolds number. An empirical correlation for predicting the overall heat transfer from the cylinder is developed for this case.
\end{abstract}

Keywords: Heat transfer; Vertical cylinder; Mixed convection; Crossflow.

\section{INTRODUCTION}

Mixed free and forced convection external flows arise when free-stream inertial and near-wall buoyant forces have strong effects on the resulting convective heat transport. Mixed convection is an important heat transfer problem that occurs in a variety of technological and industrial applications. These applications include: nuclear reactors cooled during emergency shutdown, electronic devices cooled by fans, heat exchangers placed in low-velocity environments, hot wire anemometers operated in low free stream velocity, and solar central receivers exposed to wind currents.

There are only a few papers in the literature that deal with mixed convection flow over vertical cylinders. Chen and Mucoglu [1] were the first to study such a problem for a uniform wall temperature case. Subsequently, Mucoglu and Chen [2] considered the same problem for the uniform surface heat flux case. In both cases, solutions of the governing boundary layer equations were obtained by the local nonsimilarity method [3,4].

Zukauskas and Ziugzda [5] published a study on heat transfer from a circular cylinder in air, water, and transformer oil. The effect of Re and $\operatorname{Pr}$ on both local and average heat transfer were reported. Many other researchers proposed correlations for the overall heat transfer from a circular cylinder [5-12]. However, the power indices of $R e$ and $P r$ for the overall heat transfer are different due to limited experimental results and significant differences in the experimental conditions of previous studies such as the ranges of Reynolds number and Prandtl number, and the thermal boundary condition.
The objective of the present study is to determine the average heat transfer from the measured local heat transfer rates and develop an empirical equation for the flow around the short vertical cylinder.

\section{EXPERIMENTAL PROCEDURE}

The experiments were conducted in a subsonic, recirculating ambient air wind tunnel with a $440 \times 440$ $\mathrm{mm}$ test section. The wind tunnel velocity can be varied continuously from about 0.5 to $5 \mathrm{~m} / \mathrm{s}$.

The model height $L$ to diameter $d$ ratio (aspect ratio) of 0.5 was tested in the present study. The model was hollow aluminum cylinder and was fitted with insulating ends. The model was attached on each end to an insulating section and mounted vertically in the wind tunnel. Consequently, the model was thermally finite and aerodynamically infinite. Heater elements were inserted down axial holes which were drilled at several locations around the cylinder. The copper-constantan thermocouples of $0.4 \mathrm{~mm}$ wire diameter were placed around the cylinder to measure the cylinder temperature. Thermocouples were also suspended at various interior centerline locations to measure end losses. The interior of the cylinder was filled with foam insulation. A diagram of the model is shown in Fig. 1.

The mixed convection heat transfer rate can be measured by performing an energy balance on the cylinder. The wind tunnel is operated at a particular velocity setting and the cylinder is heated. When the cylinder reaches about $100{ }^{\circ} \mathrm{C}$ the heater is turned off and the heat transfer tests start. For the case when the heater power is zero, an energy balance gives: 
$\dot{Q}_{\text {mixed }}=-m c_{p} \frac{d T}{d t}-\varepsilon \sigma A\left(T_{w}^{4}-T_{\infty}^{4}\right)-\dot{Q}_{\text {losses }}$

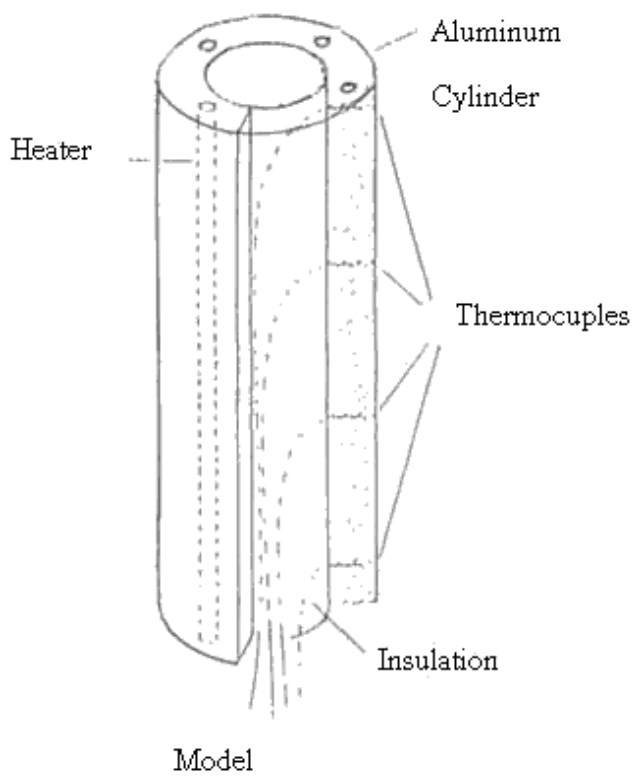

Figure 1- Model configuration.

The cylinder emissivity from tabulated data is 0.11 . Exact value is unnecessary since the adiation term is small. The cylinder and insulation temperatures are recorded by a data acquisition system. Consequently, by monitoring the rate of decay of the cylinder temperature, the free stream temperature, and the insulation temperatures, equation (1) can be solved for the mixed convection heat transfer rate. The Nusselt number is then calculated at any instant of time from:

$$
\bar{N} u=\dot{Q}_{\text {mixed }}\left\{d /\left(A k\left(T_{w}-T_{\infty}\right)\right)\right\}
$$

\section{RESULTS AND DISCUSSIONS}

The pressure measurement results for $1.1 \times 10^{3}<\mathrm{Re}<$ $3.3 \times 10^{4}$ are shown in Fig. 2. The static pressure decreases rapidly with increasing distance from the stagnation point, until it reaches a minimum value at $\theta=60^{\circ}$, downstream of the position $\theta=60^{\circ}$, the pressure begins to increase. The separation point corresponds to the beginning of the nearly constant local static pressure coefficient [8]. Separation occurs at about $80 \mathrm{deg}$ from the leading edge. The mixed convection results were found to be in agreement with accepted correlations [9] and with the experimental data of Young and Ulrich [10]. The solid line shown in Fig. 3 is the pure forced convection limit from [9].
The Reynolds number ranges investigated in [10] are similar to those simulated in the present study, but the aspect ratio range is much larger. Large aspect ratio cylinders may operate in a different flow regime than short aspect ratio cylinders, e.g., in the transition or turbulent regime compared to laminar flow for short aspect ratio cylinders. This may explain why the data of [10] are higher than for the short cylinder data of the present study.

A least-squares fit to the data for thermally short and aerodynamically infinite cylinders gives:

$$
\begin{aligned}
& \bar{N} u=0.78 \operatorname{Re}^{0.55} \operatorname{Pr}^{0.33} G^{0.0063} \quad 1000<\operatorname{Re}<5000 \\
& \bar{N} u=0.2 \operatorname{Re}^{0.6} \operatorname{Pr}^{0.33} G r^{0.00574} \quad 5000<\operatorname{Re}<40000
\end{aligned}
$$

Equation (3) represents the data to within \pm 16 percent.

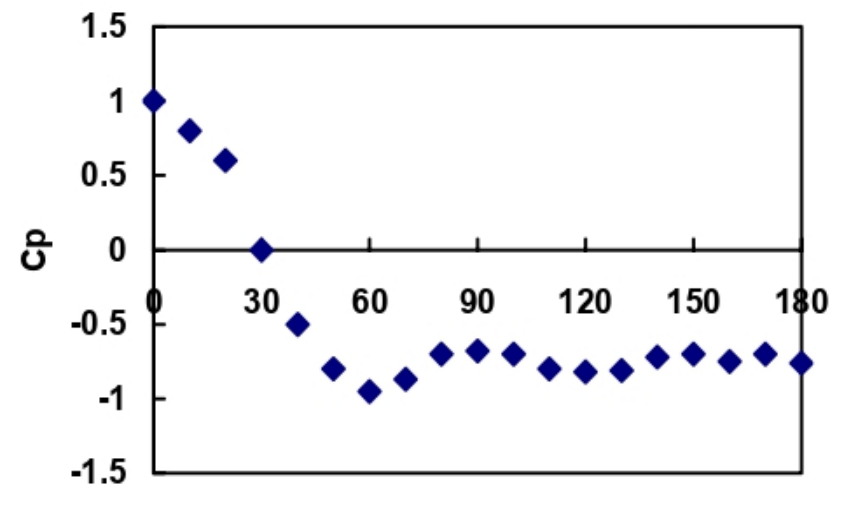

Angular position (deg)

Figure 2- Pressure distributions near the thermal leading edge.

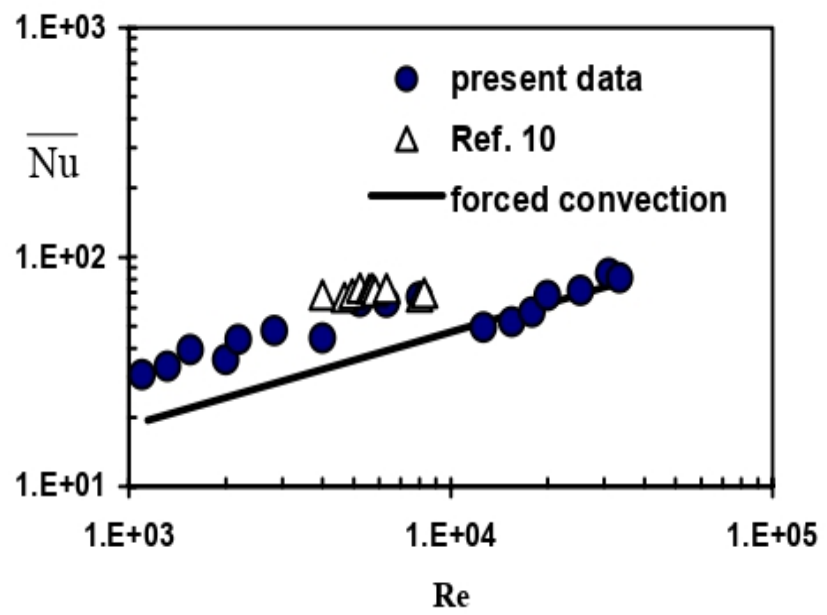

Figure 3- Average Nusselt number at different Reynolds numbers 


\section{CONCULSIONS}

The mixed convection heat transfer coefficient from smooth vertical short cylinder placed in a crossflow is measured in the present study. The Reynolds number is varied from $1.1 \times 10^{3}$ to $3.3 \times 10^{4}$ and Prandtl number 0.7 . An empirical correlation for predicting the overall heat transfer from the cylinder is developed. The value of mean Nusselt number can be calculated from the empirical equation (3) with maximum relative errors of $\pm 20 \%$. The separation point corresponds to the beginning of the nearly constant local static pressure coefficient is measured. Separation occurs at about $80 \mathrm{deg}$ from the leading edge.

\section{NOMENCLATURE}

A surface area

$\mathrm{c}_{\mathrm{p}} \quad$ specific heat

$\mathrm{Cp} \quad$ pressurecoefficient, $\mathrm{p}$ -

$\mathrm{p}_{\infty} / 0.5 \rho \mathrm{u}_{\infty}{ }^{2} \mathrm{~d} \quad$ diameter or

differential

g acceleration of gravity

$\mathrm{Gr}_{\mathrm{L}} \quad$ Grashof number based on $\mathrm{L}=\mathrm{g} \beta\left(\mathrm{T}_{\mathrm{w}^{-}}\right.$

$\left.\mathrm{T}_{\infty}\right) \mathrm{L}^{3} / \mathrm{v}^{2} \mathrm{k} \quad$ thermal conductivity

L height

m mass

$\mathrm{Nu} \quad$ average Nusselt

number $\mathrm{p}$ pressure

Pr Prandtl number

Q heat transfer rate

Re Reynolds number

t time

T temperature

\section{Greek symbols}

$\beta \quad$ coefficient of thermal expansion

$\varepsilon \quad$ emissivity

$\sigma \quad$ Stefan-Boltzmann constant

$v \quad$ kinematic viscosity

\section{subscripts}

w wall condition

$\infty \quad$ free stream condition

\section{REFRENCES}

[1] T. S. Chen, and A. Mucoglu, "Buoyancy effects on forced convection along a vertical cylinder", J. Heat Transfer 93 , pp. 198-203, 1971.

[2] A. Mucoglu, and T. S. Chen, "Buoyancy effects on forced convection along a vertical cylinder with uniform surface heat flux", J. Heat Transfer 98, pp. 523-525, 1976.

[3] E. M. Sparrow, H. Quack, and C. J. Boerner, "Local nonsimilarity boundary layer solutions", AIAA J. 8, pp. 1936-1942, 1970.

[4] E. M. Sparrow, and H. S. Yu, "Local non-similarity thermal boundary solutions", J. Heat Transfer 93, pp. 328-334, 1971.

[5] A. Zukauskas, and J. Ziugzda, "Heat transfer of a cylinder in crossflow", hemisphere pub., Washington; New York, 1985.

[6] S. W. Churchill, and M. Bernstein, "A correlating equation for forced convection from gases and liquids to a circular cylinder in cross flow", J. Heat Transfer 99, pp. 300-306, 1977.

[7] S. Sanitjai, and R. J. Goldstein, "Forced convection heat transfer from a circular cylinder in crossflow to air and liquids", Int. J. of Heat and Mass Transfer, Vol. 47, pp. 4795-4805, 2004.

[8] Z. G. Kostic, and S. N. Oks, "Fluid flow and heat transfer with two cylinders in cross flow", Int. J. Heat and Mass Transfer, Vol. 15, pp. 279-299, 1971.

[9] F. P. Incropera, and D. P. DeWitt, "Introduction to heat transfer", John Wiley and Sons, 1996.

[10] M. F. Young, and T. R. Ulrich, "Mixed convection heat transfer from a vertical heated cylinder in a crossflow", Int. J. of Heat and Mass Transfer, Vol. 26, pp. 1889-1892, 1983.

[11] N. Shah, N. Ahmed, D. Vieru, C. Fetecau, "Effects of double stratification and heat flux damping on convective flows over a vertical cylinder", Chinese Journal of Physics, Vol. 60, pp. 290-306, August 2019.

[12] C. G. Patel, S. Sarkar, S. K. Saha, "Mixed convective vertically upward flow past side-by-side square cylinders at incidence", Int. J. of Heat and Mass Transfer, Vol. 127, Part A, pp. 927-947, December 2018. 